\title{
Study of Dielectric and Thermal Conductivity Characteristics of Polyimide Composite
}

\author{
Meehye Oh, Yeoseong Yoon, Eunjin Jang, Dongjoon Moon \\ Environmental Materials R\&D Center, Korea Automotive Technology Institute, Cheonan, South Korea \\ Email: mhoh@katech.re.kr
}

How to cite this paper: Oh, M., Yoon, Y. Jang, E. and Moon, D. (2019) Study of Dielectric and Thermal Conductivity Characteristics of Polyimide Composite. Materials Sciences and Applications, 10, 197-204. https://doi.org/10.4236/msa.2019.103016

Received: October 26, 2018

Accepted: March 9, 2019

Published: March 12, 2019

Copyright (c) 2019 by author(s) and Scientific Research Publishing Inc. This work is licensed under the Creative Commons Attribution International License (CC BY 4.0).

http://creativecommons.org/licenses/by/4.0/

\begin{abstract}
The graphene is used to enhance the thermal conductivity, but it is difficult to obtain uniform dispersion and low dielectric property. We fabricate the polyimide composite with high thermal conductivity and low dielectric property. It changes the filler contents, and examines curing time and dispersion. The dispersion characteristics were quantified by absorbance measurement. The graphene $0.1 \mathrm{wt} \%$ and $\mathrm{BN} 0.5 \mathrm{wt} \%$ polyimide composites show a thermal conductivity of $6.6 \mathrm{~W} / \mathrm{m} \cdot \mathrm{K}$ by LFA (Laser Flash Analysis) and a dielectric constant of 4.6@10 GHz by SPDR (Split Post Dielectric Resonators).
\end{abstract}

\section{Keywords}

Dielectric Property, Thermal Conductivity, Polyimide Composite, Flexible PCB

\section{Introduction}

Polyimide has high heat resistance characteristics. Polyimide is the main material for flexible printed circuit board. It has a high operating temperature system. If the ambient temperature rises, both transfer rate and durability deteriorate rapidly [1]. So, the use of thermal conductive materials is important.

Currently, the electric devices require a high transfer rate at high frequency. The faster transfer rate can be achieved by lowering permittivity. Therefore, polyimide requires low dielectric properties.

Generally, graphene was used to enhance the thermal conductivity, but it is difficult to obtain uniform dispersion and low dielectric property [2].

We fabricated the polyimide composite with high thermal conductivity and low dielectric property. It changed the filler various contents, and curing time and dispersion condition. 


\section{Methods}

We used polyimide varnish (SKCKOLONPI Co.), graphene (XG science Co.) and $\mathrm{BN}$ ( $3 \mathrm{M}$ cooling filler). Graphene and $\mathrm{BN}$ in solvent were dispersed using ultrasonic at $300 \mathrm{~W}$ for $3 \mathrm{~min}$. And then mixed with polyimide varnish using plantary mixer (THINKY Co.) at $2000 \mathrm{rpm}$ during 4 min (involved degasing time). Thin film was prepared by the knife coating using micro gauge device with adjustable applicator.

We observed dispersion stability of fillers in Dimethylformamide (DMF). The solutions were left for maximum 4 days. When the solution was not separated, the condition was determined. When it was applied $300 \mathrm{~W}$ ultrasonicwave for 3 min, the dispersion stability was good. The composite film was prepared by mixing PI varnish and graphene solution using the planetary mixer at $2000 \mathrm{rpm}$ for $2 \mathrm{~min}$. The solvent was removed at $100^{\circ} \mathrm{C}$ for $5 \mathrm{~min}$ in a convection oven. And then, it was cured for 20 minutes at $200^{\circ} \mathrm{C}$. The curing time was long, because the catalyst was not used. The filler contents in composite are graphene 0.1 wt\%, graphene $(\mathrm{G})$ 0.1-BN(B) 0.1 wt\%, G 0.1-B 0.3 wt\%, G 0.1-B 0.5 wt\%, G 0.1-B $0.7 \mathrm{wt} \%$, G 0.1-B $0.9 \mathrm{wt} \%$. Figure 1 shows diagram of the materials mixing, film making and curing process.

The curing behavior was predicted using LT-451 Dielectric Cure Monitor. The dispersion measured by UV-vis, and thermal conductivity using laser flash \& hot disc. And then, the dielectric property measured using SPDR network analyzer at $1-10 \mathrm{GHz}$.
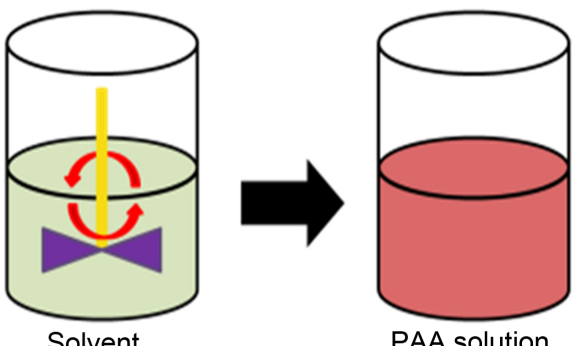

PAA solution
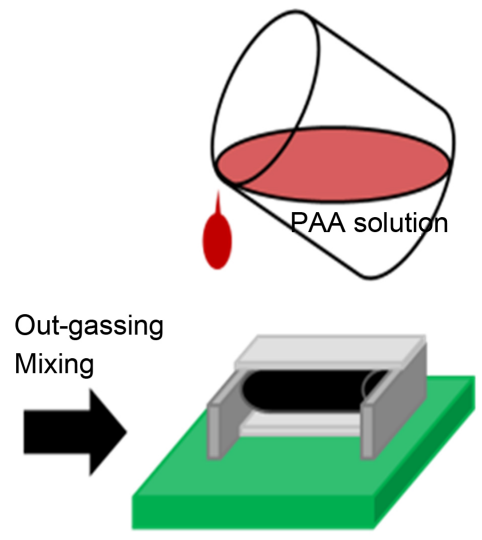

Film casting
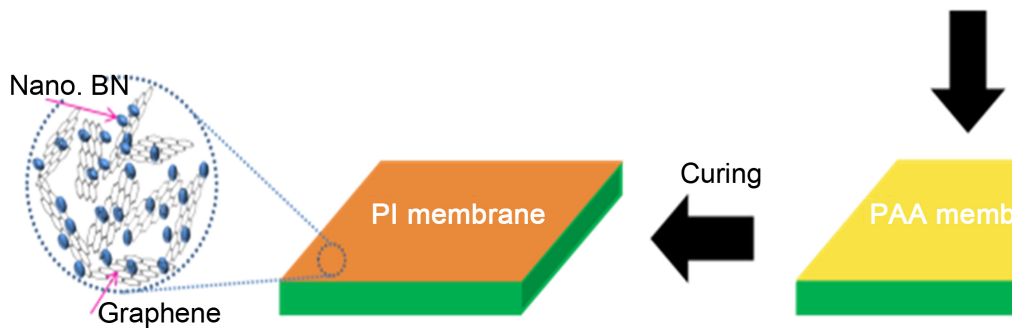

Curing

Figure 1. Manufacturing process of PI composite film. 


\section{Results and Discussion}

\subsection{Curing Behavior}

If the physical viscosity of curable polymer increases, the ionic viscosity increases. Increasing ionic viscosity is indicated by ionic current.

Figure 2 shows the PI and PI-graphene composite curing behavior with temperature. Depending on the curing temperature and holding time, the volatility of the solvent and the degree of curing of PAA, which can influence the film performance, are different.

During the volatilization of the solvent, bubbles may be generated on the surface or inside in the film to degrade performance. Therefore, the temperature and hold time must be optimized in the step-by-step curing program.

At a curing temperature of $100^{\circ} \mathrm{C}$, the viscosity of PI began to increase after $80 \mathrm{~min}$ and PI-graphene composite after $15 \mathrm{~min}$. The viscosity of PI-graphene composites is constant after about $12 \mathrm{~min}$. At $200^{\circ} \mathrm{C}$ of curing temperature, PI showed a large viscosity change after 5 min and becoming constant after around $15 \mathrm{~min}$. In the case of PI-graphene composites, the curing started after $3 \mathrm{~min}$ and viscosity value is becoming constant within $10 \mathrm{~min}$. Compared curing time
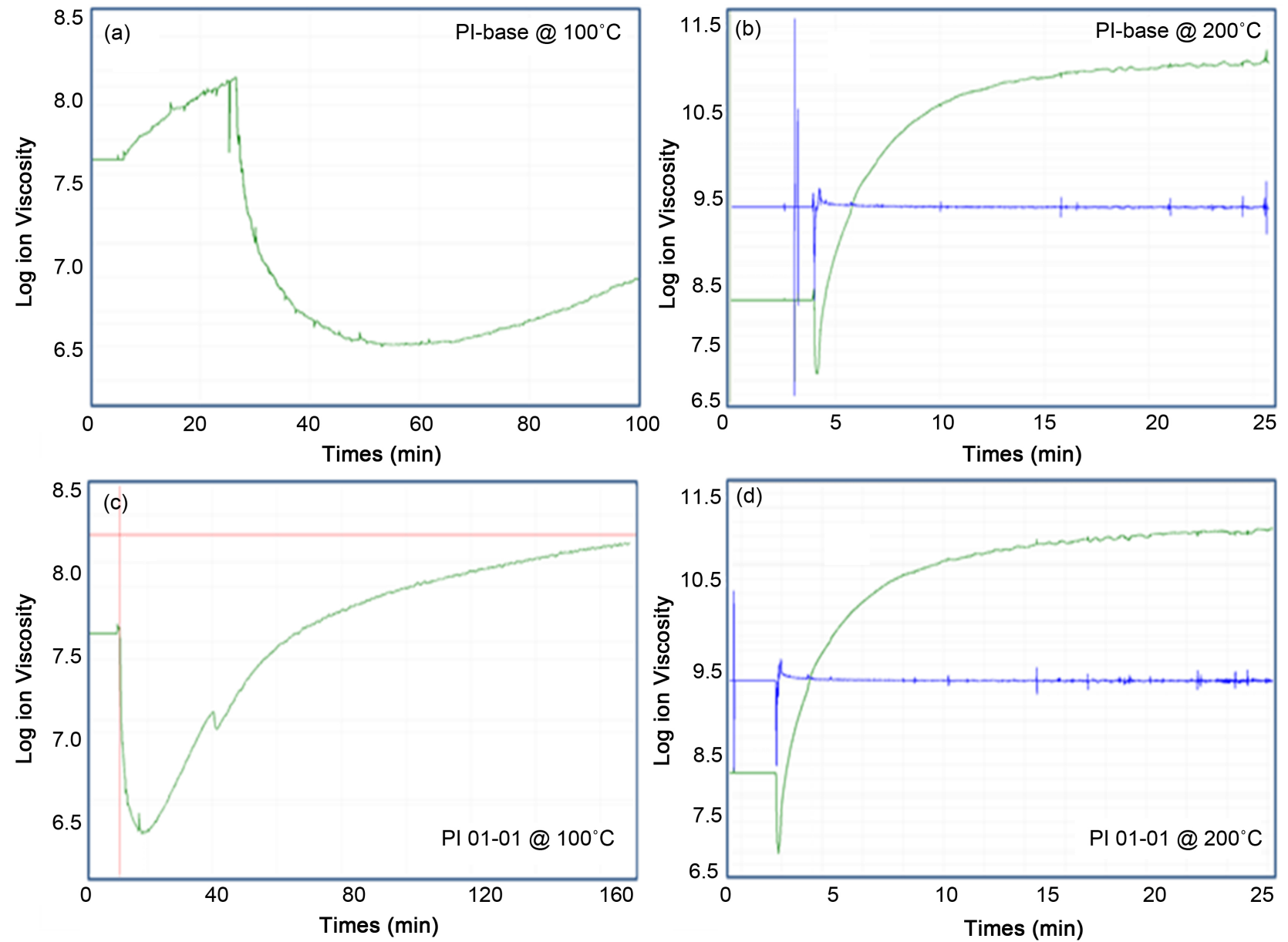

Figure 2. Measuring of Viscosity by dielectric curing monitoring. (a) PI @100 ${ }^{\circ} \mathrm{C}$; (b) PI @200 $\mathrm{C}$; (c) PI composite @100 $\mathrm{C}$; (d) PI composite @ $200^{\circ} \mathrm{C}$. 
with PI and PI-graphene composites, it was more than $10 \mathrm{~min}$ at $200^{\circ} \mathrm{C}$ and more than $30 \mathrm{~min}$ at $100^{\circ} \mathrm{C}$. The curing time difference is due to graphene has higher thermal conductivity effect than the polymer material. It is guessed that the volatile of the solvent on the graphene interface and the improved thermal conductivity of the material. I could have expected that the better the thermal conductivity of the composite material, the lower curing temperature and the shorter time.

\subsection{Dispersion}

The absorbance of the film was measured by UV-vis. High absorbance, the better the filler dispersion in the film. We used Horn type ultrasonic homogenizer as output $300 \mathrm{~W}$ in $20 \%$ of maximum power. The solution with graphene was dispersed in various ultrasonic time 1, 3, 5, 10, $15 \mathrm{~min}$. After the $3 \mathrm{~min}$ or longer, the dispersion remained more than $48 \mathrm{hrs}$ and that minimum time selected. Figure 3 shows the ultrasonic dispersion solution with time variation.

The dispersion degree measurement using the UV-vis was mainly performed as mainly used measuring the dispersion degree of CNT. The graphene is slightly different from the structure of CNT (CarbonNanoTube) but it is possible to measure the dispersion using UV-vis. It is difficult to quantify the degree of dispersion of highly concentrated solutions using UV-vis. A solution with a high degree of dispersion and low concentration are easy to measure the UV-vis spectrum. However, when the dispersion is poor, the UV-vis spectrum has high noise and low reliability due to particle agglomeration.

From Beer-Lambert's law, Equation (1) can be expressed for components [3] [4].

$$
A=\epsilon \cdot t \cdot c=\epsilon_{R} \cdot t \cdot c_{R}^{*}+\epsilon_{f} \cdot t \cdot c_{f}^{*}
$$

where:

$A$ : absorbance,

$\epsilon_{R}$ : molar abs. coefficient of resin,

t: thickness,

$c_{R}^{*}$ : concentration of resin,

$\epsilon_{f}$ : molar abs. coefficient of filler,

$c_{f}^{*}$ : concentration of filler.

The products of the molar extinction coefficient and the concentration of components are $a$ and $b$.

$$
a=\epsilon_{R} \cdot c_{R}^{*}, \quad b=\epsilon_{f} \cdot c_{f}^{*},
$$
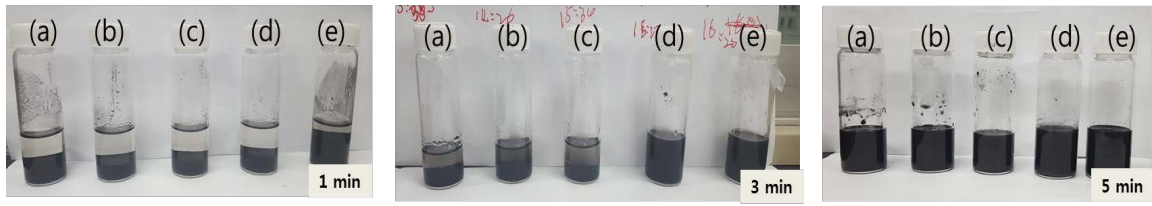

Figure 3. Ultrasonic dispersion solution with time variation. (a) PI 01-01; (b) PI 01-03; (c) PI 01-05; (d) PI 01-07; (e) PI 01-09. 
From this, effective concentration factor is $=\frac{A /(t-a)}{b \cdot c_{f}}$. In this case, $\beta$ represents a value of 0 to 1 . When $\beta$ is 1 , it is completely dispersion [3].

The absorbance of the composite material, which is not affected by each component, can be judged to start at about $440 \mathrm{~nm}$. Therefore, the $\beta$ value at $440 \mathrm{~nm}$ was calculated and shown in Table 1 . As shown in Table $1, \beta$ value is low. $\beta$ showed a low value of 1 or less, according to the calculation results. The higher the degree of dispersion, $\beta$ is closer to 1 , but in this study, the value is 0.1 or less.

The non-polar graphene in the DMF, polar protic solvent, is easier to aggregate. Therefore, it is considered that it is necessary to use a dispersing additive or to increase the external energy so that the substitution reaction can be facilitated. The coefficients calculated from Figure 4 are shown in Table 1.

\subsection{Thermal Conductivity \& Dielectric Properties}

Graphene increases not only the thermal conductivity of composites, but also the dielectric constant. Boron nitride was additionally used to lower the dielectric constant while maintaining the high thermal conductivity. The thermal conductivity of $3 \mathrm{wt} \%$ graphene polyimide composite is about $6 \mathrm{~W} / \mathrm{m} \cdot \mathrm{K}$ and dielectric constant $\left(D_{k}\right)$ is about 2.2 . In general, the permittivity of polyimide is 3.4.

Table 1. The value of constituent materials dispersion coefficient of polyimide composite film.

\begin{tabular}{ccccccc}
\hline & PI 01-00 & PI 01-01 & PI 01-03 & PI 01-05 & PI 01-07 & PI 01-09 \\
\hline$\epsilon_{R}$ & 0.092 & 0.109 & 0.045 & 0.029 & 0.015 & 0.022 \\
$\epsilon_{f}$ & 0.065 & 0.096 & 0.039 & 0.025 & 0.012 & 0.019 \\
$\beta$ & 0.111 & 0.058 & 0.034 & 0.026 & 0.022 & 0.020 \\
\hline
\end{tabular}

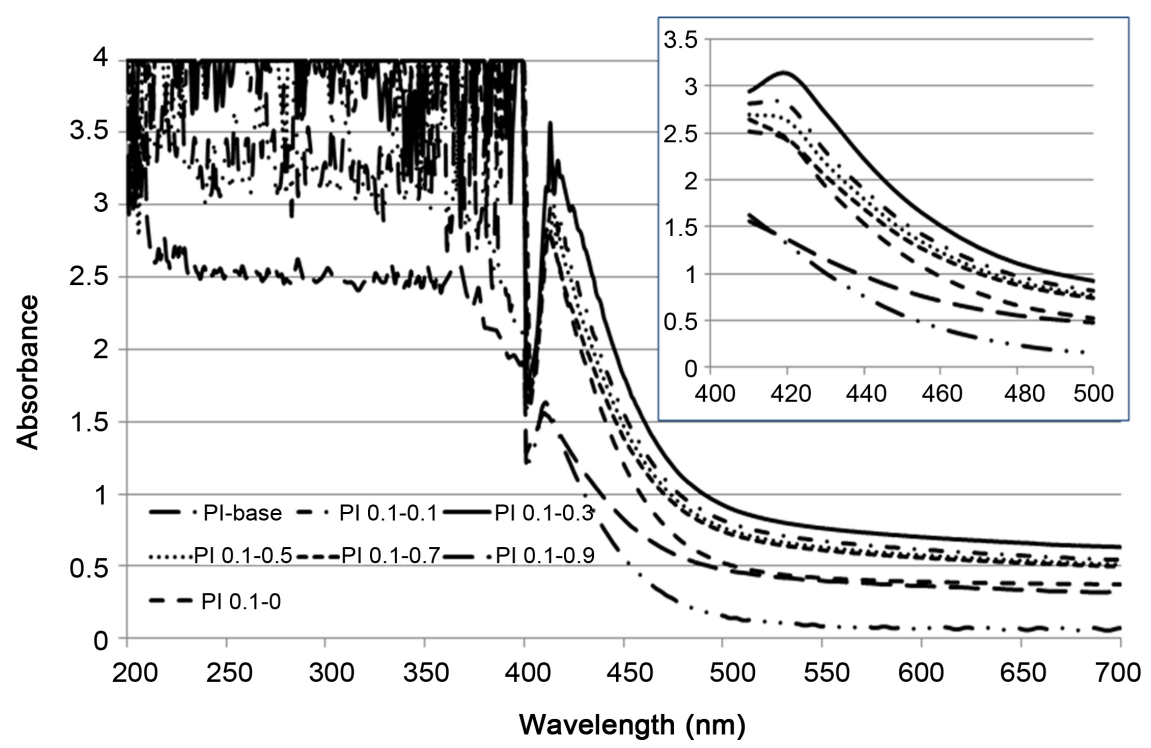

Figure 4. UV-vis spectrum of polyimide composite material. 
However, the low the permittivity, the higher the transmission speed of the mobile device. Therefore, the dielectric constant of flexible printed circuit board is required to be 5 or less. Graphene composites have excellent in-plane thermal conductivity, but thru-plane thermal conductivity is low. The graphene and BN were combined to complement the thermal conductivity and permittivity. We predicted that graphene could make connections between BN particles. The PI composite was compounded with multi-filler to fill the gap between graphenes. The network of thermal path was formed by the difference in shape and size of graphene and BN. Figure 5 is a SEM image of fillers in PI composite.

As shown in Table 2, we could obtain a thermal conductivity of about 6 $\mathrm{W} / \mathrm{m} \cdot \mathrm{K}$ and a dielectric constant of about 4 in composite materials. However, if the dispersive is better, the thermal conductivity improvement and the dielectric constant reduction effect will be further increased.

DMF and graphene are factors that increase the permittivity of polyimide composites. However, in the process of manufacturing the polyimide film, the solvent, DMF, is volatilized. In the curing process of the polyimide film, the temperature condition was optimized so as not to affect the dielectric constant by sufficiently volatilizing the DMF to leave no residue.

As shown in Table 2, the dielectric loss $\left(D_{\mathrm{f}}\right)$ is extremely low. Dielectric loss is caused by electric conduction and polarization due to the impurities contained

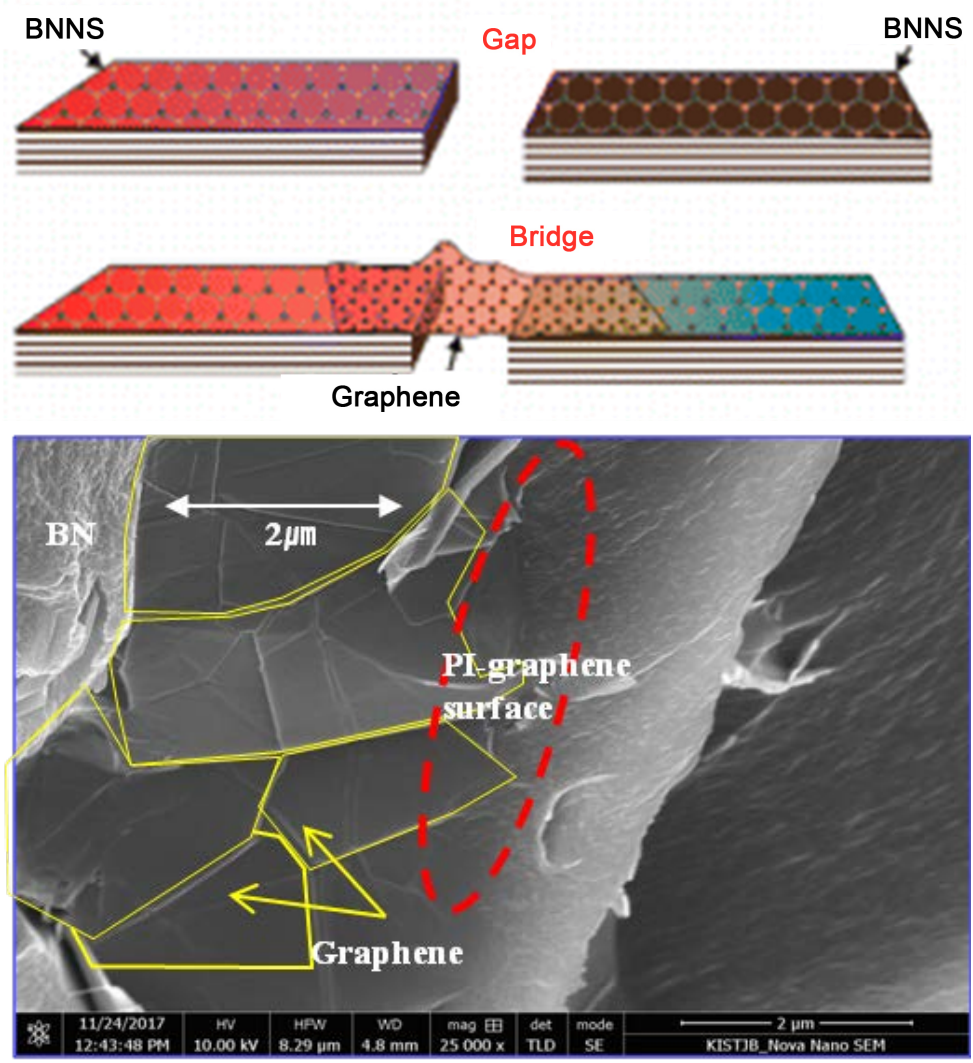

Figure 5. Diagram of filler structure and SEM morphology in polyimide composite. 
Table 2. Properties of polyimide-graphene composites.

\begin{tabular}{ccccccc}
\hline & \multirow{2}{*}{$\begin{array}{c}\text { Thick. } \\
(\mu \mathrm{m})\end{array}$} & \multicolumn{2}{c}{ Thermal conductivity (Laser Flash Analysis) } & \multicolumn{2}{c}{ Permittivity } \\
\cline { 3 - 7 } & $\mathrm{TC}^{\mathrm{a}}$ & $\mathrm{TD}^{\mathrm{b}}$ & $\mathrm{HC}^{\mathrm{c}}$ & $\mathrm{D}_{\mathrm{k}}$ & $\mathrm{D}_{\mathrm{f}}$ \\
\hline PI 0.1-00 & 22.70 & 8.185 & 11.708 & 1.032 & & \\
PI 0.1-01 & 11.95 & 4.575 & 6.472 & 1.014 & 4.338 & 0.017 \\
PI 0.1-03 & 13.58 & 3.344 & 4.704 & 1.035 & 4.773 & 0.018 \\
PI 0.1-05 & 14.98 & 6.674 & 9.878 & 1.03 & 4.646 & 0.018 \\
PI 0.1-07 & 13.97 & - & - & - & 4.914 & 0.022 \\
PI 0.1-09 & 13.70 & 7.564 & 11.098 & 0.99 & 5.381 & 0.026 \\
\hline
\end{tabular}

${ }^{a}$ TC: Thermal Conductivity (W/m·K), ${ }^{b} \mathrm{TD}$ : Thermal Diffusivity $\left(\mathrm{mm}^{2} / \mathrm{s}\right),{ }^{\mathrm{C}} \mathrm{HC}$ : Heat Capacity $(\mathrm{J} / \mathrm{g} / \mathrm{K})$.

in the material. Therefore, it can be predicted that the graphene acts as a functional filler that enhances thermal conductivity rather than acting as an impurity.

\section{Conclusions}

From this study, the followings were obtained. In order to improve the properties of the polyimide composite, graphene and BN filler were compounded. The dispersion characteristics were quantified as $\beta$ value from absorbance measurement. The optimal conditions were determined as a function of ultrasonic time and filler concentration.

The graphene $0.1 \mathrm{wt} \%$ and $\mathrm{BN} 0.5 \mathrm{wt} \%$ polyimide composites showed a thermal conductivity of $6.6 \mathrm{~W} / \mathrm{m} \cdot \mathrm{K}$ by LFA and a dielectric constant of 4.6 by SPDR $@ 10 \mathrm{GHz}$. The heat transfer effect was enhanced by the network between fillers. However, it is necessary to continuously observe the tendency of dielectric constant and loss.

\section{Acknowledgements}

This paper is the result of industrial core technology development project by supported by Ministry of Commerce, Industry and Energy jointly and SKCKOLONPI Co.

\section{Conflicts of Interest}

The authors declare no conflicts of interest regarding the publication of this paper.

\section{References}

[1] Kim, J., Kwon, J., Lee, D., et al. (2016) Heat Dissipation Properties of Polyimide Nanocomposite Films. Korean Journal of Chemical Engineering, 33, 3245-3250. https://doi.org/10.1007/s11814-016-0158-7

[2] Park, Y.K. and Cho, C.H. (2016) Effects of Additives on the Mechanical and Thermal Properties of Epoxy-Based Nanocomposites Produced Using Sonication. Ko- 
rean Journal of Chemical Engineering, 33, 1938-1941.

https://doi.org/10.1007/s11814-016-0034-5

[3] Lee, S.-B., Jeong, B.-H., et al. (2011) Quantitative Dispersion Evaluation of Carbon Nanotubes Reinforced Polymer Nano-Composites. Polymer(Korea), 35, 60-65.

[4] Rahimpour, A. (2011) Preparation and Modification of Nano-Porous Polyimide (PI) Membranes by UV Photo-Grafting Process: Ultrafiltration and Nanofiltration Performance. Korean Journal of Chemical Engineering, 28, 261-266.

https://doi.org/10.1007/s11814-010-0350-0 